\title{
Assessment of High Speed Spindle Accuracies
}

\author{
1 A.P.Arun, 2 A.Faizur Rahman, 3 V.Manivelmuralidaran, 4 K.Krishnamoorthi \\ 1 Department of Mechanical Engineering, Kumaraguru College of Technology, Coimbatore \\ arunnical@gmail.com \\ 2 Department of Mechanical Engineering, CSI College of Engineering, Ooty \\ faizurmech@gmail.com \\ 3 Department of Mechanical Engineering, Kumaraguru College of Technology, Coimbatore \\ amritamani@gmail.com \\ 4 Department of Mechanical Engineering, Kumaraguru College of Technology, Coimbatore \\ krishnamoorthipsg@gmail.com
}

\section{ABSTRACT}

The spindle error contributes to 25 percent of the error sources of the work piece in- accuracies. The 70 percent of the spindle errors are due to thermal errors that occurs in the spindle. The heat generation in high-speed built-in motorized spindle is of important concern in high speed machining. It is necessary to predict the heat generation in spindle body virtually so as to judge machine capability. The thermal prediction will also help in taking precautions to avoid inaccurate parts being produced as well to avoid the chances of bearing seizure leading to catastrophic failure of spindle. In this paper the thermal behavior of high-speed motorized spindle is investigated through three dimensional analysis and experimentation validation is given for the same.

\section{Indexing terms/Keywords}

CNC machine tool, high- speed motorized spindle, thermal error, finite element simulation

\section{Academic Discipline And Sub-Disciplines}

\author{
Mechanical Engineering
}

\section{SUBJECT CLASSIFICATION}

Machining

\section{TYPE (METHOD/APPROACH)}

Experimental assessment and analysis

\section{INTRODUCTION}

The metal cutting machine device showcase has put the machine-tool developers to make more adaptable machines at focused cost. The flexibility required is in terms of performance over wide range of cutting parameters with close tolerance of components being produced. The desire of adaptability is because of manufacturing agility of the shop floor as of late. [1-3]. High speed machine tool is one of the basic needs in high speed machining which caters to wide range of machining parameters with tight tolerance band. Like in conventional machines the power in these machines is not transmitted via the power transmitting elements like belt, chain, gear etc. The spindle is equipped with built in motor without the frame.

High-speed motorized spindle is the main part of high speed machine tool. It is also the main heat source of the machine tool[4]. The rigidity and accuracy are the prime characteristics of motorized spindle. The impact of cutting forces on spindle is mostly taken care during configuration/design phase of motorized spindle itself. However there are a few uncontrollable and unpredictable components that are hard to account for during design stage. These will cause error in spindle position by deforming it and ultimately parts produced will be defective. One of such uncontrollable component is the thermal errors in high speed spindle. The primary cause for deformation of motorized spindle is heat produced by the motor power loss which includes mechanical loss, electrical loss, magnetic loss and additional loss, secondly the bearing's friction loss. The thermal deformation will severely reduce the accuracy of parts being produced if these sources of machine deformation causes are not dealt properly. As such in high speed machining, thermal behavior is prime factor in controlling the accuracy level and is directly proportional to the spindle speed. In addition to accuracy level of components being produced, thermal growth of spindle is one of the major causes for spindle seizure. Simulation results of thermal analysis will help in error budgeting of machine tool so as to judge the machine tool capabilities [5]. The simulation results will also be helpful in error compensation of machine tool [6-8] and also caters the need of agile manufacturing [9].

In this paper high-speed motorized spindle of vertical machining center is taken as case study and the thermal behavior analysis is done using finite element method. Later the three dimensional thermal analysis is validated by experimentation.

\section{DETAILS OF THE SPINDLE}

The spindle used for the analysis is $4.7 \mathrm{~kW}, 40000 \mathrm{rpm}$, oil cooled high-speed motorized spindle. The cooling is provided around stator by passing coolant in cooling jacket. The coolant used is spin-2 oil, which enters from cooling tower, a separate system away from the machine structure (not shown in the figure). The coolant oil is maintained between 22 $30^{\circ} \mathrm{C}$. 


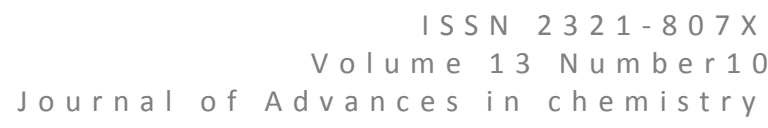

Fig. 1 shows the spindle held between two sets of angular contact bearings on front side (GMN SM 6005P4 class $(\phi 25 \times \phi 47 \times 12))$ and the rear bearing is preloaded by springs which helps for lower axial stiffness of the spindle unlike in rigid preloaded spindle (rear bearing is SNFA VEX17 P4 class $(\phi 17 X \phi 35 X 10))$. The front ball bearing is hybrid type, where ceramic balls are used and these bearings are proved to be better in performance than steel ball bearings.

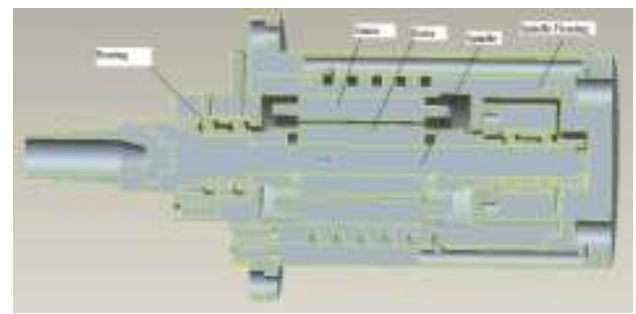

Figure 1 : Details of High Speed Motorized Spindle

\section{HEAT GENERATION SOURCES OF HIGH SPEED SPINDLE}

In a motorized spindle, the main sources of heat are;

- Heat generated due to built in motor power,

- Heat generated due to bearing friction.

\section{Heat generated due to motor power loss}

The causes of power loss in electric drives are, the heat generation in rotor and stator. The power loss can be categorized into four different types viz mechanical loss, electrical loss, magnetic loss and additional loss. The first three losses are the major contributors of power loss and the last one additional loss is about $1-5 \%$ of rated power. Copper losses are function of current flowing through stator and rotor windings and is given by [10],

$$
P_{c u}=r_{s} I_{s}^{2}+r_{r}^{\prime} I_{r}^{\prime 2}
$$

where, $r_{s}$ is stator resistance, $r_{r}^{\prime}$ is rotor resistance, $I_{s}$ is stator current, $I_{r}^{\prime}$ is rotor current. Iron losses are due to eddy current and hysteresis given by,

$$
P_{F e}=\left[k_{e}\left(1+s^{2}\right) a^{2}+k_{h}(a+s) a\right] \phi_{m}^{2}
$$

where, $k_{e}, k_{h}$ are eddy current and hysteresis coefficients, $s$ is slip, $a$ is supply frequency and $\phi_{m}$ is air gap flux. When the motor runs under normal conditions $s \leq 1$, the motor iron losses can be neglected. Lastly, stray losses which arise on copper and iron of the motor is given by,

$$
P_{s t r}=c_{z b} I_{s}^{2}+c_{s} \phi_{m}^{2} I_{s}^{2}+c_{e} a I_{s}^{2}
$$

where, $c_{z b}, c_{s}$ and $c_{e}$ are stray loss coefficients and $I_{s}$ is stator current, $\mathbb{c}_{m}$ is air-gap flux. Shuhong et al [12] have considered the total electric power loss distribution as heat generation by stator as $2 / 3$ of total power loss and $1 / 3$ power loss in rotor, whereas and Boys et al [13] have taken same proportion for copper and iron losses respectively. The losses stated in this section are in case of an AC motor, and the same are considered for estimating the losses in high speed motorized spindle. In vector control of the induction motor, the iron loss is neglected on the assumption that iron loss is very small. Even then, in the high speed induction motor drive, the loss cannot be neglected because the loss is relatively large at the top speed [14].Including the mechanical losses, the electrical losses and other losses are considered in this paper. Bernd et al [15] have given another method of estimating the high-speed motorized spindle losses using the motor efficiency.

\section{Heat generated by the bearing friction}

According to Palmgren [16] the heat generation in bearing constitutes two torques, namely load independent friction moment and another torque causing the heat loss is, load dependent friction moment given respectively,

$$
M_{0}=10^{-7} f_{0}(\gamma * n)^{2 / 3} d_{m}^{3}
$$

where, $f_{o}$ is factor that depends upon type of bearing and lubrication, $\gamma$ is kinematic viscosity of oil ( $\left.\mathrm{mm}^{2} / \mathrm{s}\right), n$ is spindle speed in $\mathrm{rpm}, \mathrm{d}_{\mathrm{m}}$ is bearing pitch diameter in $\mathrm{mm}$, and

$$
M_{1}=f_{1} P^{a} d_{m}^{b}
$$

where, $f_{1}$ is factor that depends upon type of bearing and lubrication. These equations are used to calculate the heat generated in both front and rear bearings of the high-speed motorized spindle. 


\section{HEAT DISSIPATION PHENOMENON AND THE MOTORIZED SPINDLE}

The heat in high speed motorized spindle is dissipated from motor power loss and bearings by convection and conduction.

\section{Heat Convection Between Circulating Oil And Motor}

The spindle coolant oil (spin-2) circulates in the square groove around the stator jacket and takes away the motor heat. The groove can be considered as rectangular conduit. Knowing flow rate the fluid condition is recognized whether turbulent or laminar. Equations 6-8 are used to estimate the convective heat transfer coefficient of circulating spin-2 oil.

$$
N_{u}=0.023 R_{e}^{0.8} P_{r}^{0.33}
$$

(for $R_{e}>2000$, flow is turbulent)

$$
\begin{aligned}
& h=N_{u} \frac{k}{L_{c}} \\
& L_{c}=4 \frac{A_{c}}{P}
\end{aligned}
$$

where $N_{u}$ is Nusset number, $k$ is thermal conductivity of oil $\left(\mathrm{W} / \mathrm{m}^{0} \mathrm{k}\right), L_{c}$ is effective length of channel(mm), $A_{c}$ is cross section area of the conduit $\left(\mathrm{mm}^{2}\right)$ and $P$ is perimeter $(\mathrm{mm})$. For two dimensional analysis the continuous helical coolant passage is considered as independent rings since the numerical model is axi-symmetric in nature.

\section{Convective coefficient at stator air gap and rotor air gap(front and rear side of stator-rotor)}

The air adjacent to stator will be swirling even though the stator is not rotating, this is because of the small air gap passage and effect of rotor rotation. The convective coefficient is calculated assuming the air passing over flat plate (forced convection) [4]. The corresponding formulae are,

$$
R_{e}=u \frac{L}{\gamma}
$$

Where, $\gamma$ is kinematic viscosity of air at operating condition, $u$ is peripheral velocity of air moving adjacent to stator/ rotor and $L$ is circumferential length of stator/rotor. Another relation used is,

$$
N_{u}=h \frac{D}{k}=C\left(R_{e}\right)^{n} P_{r}^{0.33}
$$

where $C, n$ are constants [17].

\section{Convective coefficient between stator and rotor air gap}

The air gap between stator and rotor is considered as flow of air between annular rings. Though the air viscosity is lower, the tight air gap between the rotor and the stator of the electric motor may produce some power loss. This power loss is transformed into heat inside the volume of the stator and rotor [15]. The corresponding formulae to calculate the same are similar to section IV B.

\section{Convective heat transfer coefficient around the main body (outer surface)}

As the spindle alone will be rotating in main body, the air adjacent to main body will take away the heat with natural convection. It is assumed that the convective heat transfer coefficient of air due to natural convection is $10 \mathrm{~W} / \mathrm{m}^{20} \mathrm{C}[4]$.

\section{FINITE ELEMENT ANALYSIS OF HIGH SPEED MOTORIZED SPINDLE}

\section{Finite element Model}

For three dimensional analysis ANSYS work bench software is used. The IGES format of the three dimensional model is imported in the ANSYS work bench environment before applying the boundary conditions. The neutral IGES is created using any of the modeling software.

\section{Assumptions in the analysis}

For three dimensional analysis assumptions like coolant flowing through pipe, uniform convection all along tube is taken [18]. The boundary condition for heat generation in ball bearings is applied as per volume of ball. 
The results of the three dimensional Analysis is shown in the Figure 3. The feature of using probes to check the results at the desired location is used and the temperature values at the front bearing outer race, stator, spindle nose and the tool tip. The Table 1 shows the temperature values.

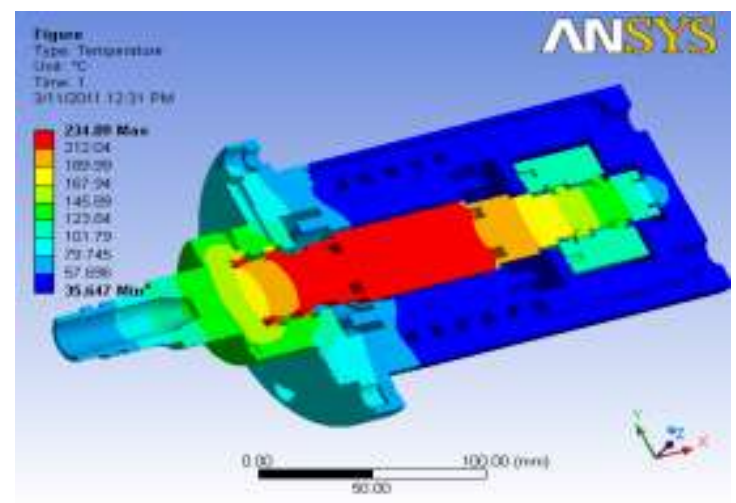

Figure 3. Ansys Result

Table 1 Results of the FEM Analysis

\begin{tabular}{|c|l|c|}
\hline S.no & \multicolumn{1}{|c|}{ Location } & Temp in degree Celsius \\
\hline 1 & Front bearing outer race & 119.65 \\
\hline 2 & Stator & 62.789 \\
\hline 3 & Spindle nose & 125.21 \\
\hline 4 & Tool tip & 58.136 \\
\hline
\end{tabular}

\section{EXPERIMENTAL VALIDATION}

The results obtained from the FEM analysis are validated by conducting an experimentation on the same spindle by measuring the temperature values at the required locations using thermocouples. Figure 4 shows the experimental setup and the Figure 5 shows the comparison between FEM and the experimental results.

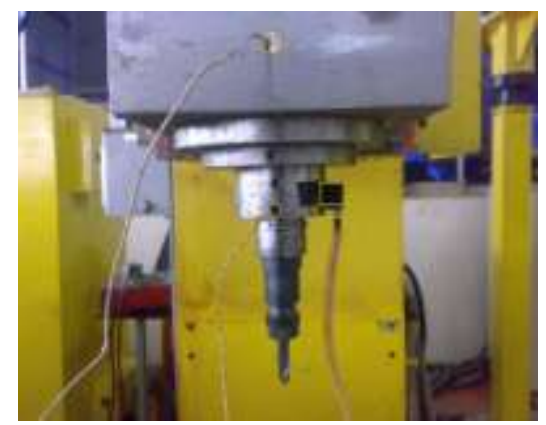

Figure 4 Experimental setup

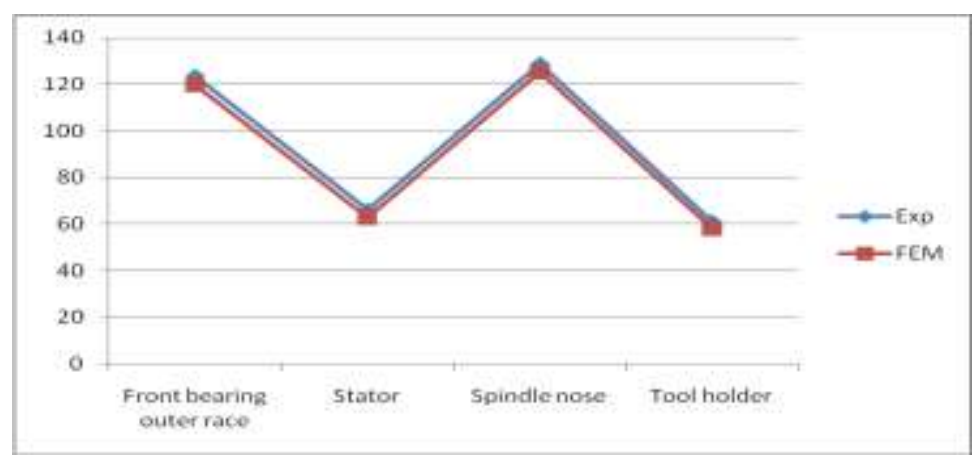

Figure 5 Graph showing FEM and Exp Results 


\section{CONCLUSIONS}

The three dimensional Analysis is carried out and the deformation in the Spindle is found out which affects the wok part accuracies. The deformations of the spindle should be given much importance in precise machining. The thermal errors of the spindle are investigated and then appropriate methods like correcting it in the design stage, adaptive control and calibration of the machine tool can be done.

\section{REFERENCES}

1. Shen C.H 1996 The importance of diamond coated tools for machining agile manufacturing and Dry Machining", Surface and Coatings Technology, 86-87, pp. 672-677.

2. Gunasekaran.A 1998 Agile manufacturing: enablers and an implementation framework Int. j. prod. res., , vol. 36, no. 5, pp. 1223- 1247.

3. Gunasekaran.A 1999 Agile manufacturing: A framework for research and development", Int. J. Production Economics 62 pp, 87-105.

4. Haitao Zhao , Jiang Yang, Jinhua Shen, 2007 Simulation of thermal behavior of CNC machine tool spindle, International Journal of Machine Tools \& Manufacture, 47, pp.1003-1010.

5. Ramesh R, Mannan M A, Poo A N 2000 Error compensation in machine tools - a review Part I: geometric, cutting-force induced and fixture dependent errors", International Journal of Machine Tools \& Manufacture, 40, pp. 1235-1256

6. Wang S.M. and Ehmann K.F , 1992 Volumetric Error Compensation for Multi-Axis Machines IEEE, International Conference on Systems, Man, and Cybernetics, Chicago, October 18-21, pp.183-188.

7. Ziegert John C. and Kalle Prashant 1994 Error compensation in machine tools: a neural network approach", Journal of Intelligent Manufacturing 5, pp.143-153.

8. Li X, Real-Time Prediction of Work piece Errors for a CNC Turning Centre 2001 Part 2. Modelling and Estimation of Thermally Induced Error", Int J Adv Manuf Technol 17, pp.654-658

9. Wang.Z.Y, Rajurkar K.P, and Kapoor.A 1996 Architecture for Agile Manufacturing and its Interface with Computer Integrated Manufacturing, Journal of Materials Processing Technology, 61, pp. 99-103.

10. Kioskeridis Iordanis and Nikos Margaris, 1996 Loss Minimisation in Induction Motor Adjustable-Speed Drives, IEEE Transactions on Industrial Electronics, Vol-43, No 1, February pp. 226-231.

11. http://www.reliance.com/mtr/b7087_5/b7087_5_2.

12. Xiao Shuhong, Zhang Bolin, 2004 Finite Element Simulation on Thermal Properties of High-speed Motorized Spindle, Journal of Information \& Computational Science 1:2 , pp. 269- 274.

13. Boys J.T, Miles M.J 1994 Empirical thermal model for inverter-driven cage induction machines, IEE. ProcElectr.Power Appl, Vol.141, No.6, November 1994, pp.360-372.

14. Tsuneo Kume, Toshihiro Sawa, , Toshitaka Yoshida, Mitsujiro Sawamura, and Mitsuo Sakamoto 1992 A Highspeed Vector-Controlled Spindle Motor Drive with Closed Transition Between with Encoder Control and without Encoder Control IEEE Transactions on Industry Applications, vol. 28, No. 2 pp. 421-426.

15. Bernd Bossmanns and Jay F. Tu 2001 A Power Flow Model for High Speed Motorized Spindles-Heat Generation Characterization, J. Manuf. Sci. Eng. Volume 123, Issue 3, pp.494 -505.

16. Harris.T.A, 1991 Rolling Bearing Analysis, $3^{\text {rd }}$ Edition, John Wiley and Sons,

17. Yunus A Cengel, 2007 Heat and Mass Transfer, $3^{\text {rd }}$ Edition, Tata McGraw-Hill,.

18. Xiao Shuhong, Zhang Bolin 2004 Finite Element Simulation on Thermal properties of high-Speed Motorized Spindle", Journal of Information \&Computational Science 1:2, pp.269- 274.

19. V.Prabhu Raja 2004 Studies on thermal behaviour of motorized high speed spindles", PhD Thesis, 2004. 